\title{
Risk Based Ranking Using Component Cost Importance Measure
}

\author{
RamaKoteswara Rao Alla ${ }^{a^{*}}$, G.L Pahuja ${ }^{b}$, J.S Lather ${ }^{c}$ \\ ${ }^{a}$ Research Scholar, Electrical Engineering Department,National Institute of Technology Kurukshetra, \\ Kurukshetra,136119,India. \\ ${ }^{b, c}$ Professor, Electrical Engineering Department, National Institute of Technology Kurukshetra.
}

\begin{abstract}
The present day systems are increasing in complexity in terms of both the size and functionality. Also society demands these systems to be ultra-reliable. Reliability evaluation and optimization techniques play a major role in these regards. However reliability evaluation \& optimization techniques do not give any idea about maintenance, risk involved and related cost incurred and criticality of system components or subsystems. Important measures (IM) exist in literature that identify the weak components i.e critical components and give ranking to them. Recently some work has appeared on Cost Importance Measure (CIM). There are number of mistakes/short comings in the paper Cost-related importance measure by Ming et.al. Definition of CIM given in general and the same used for computation of CIM of component $\mathrm{x}_{\mathrm{i}}$ have appeared differently (Different definitions for $\mathrm{CIM})$. $\mathrm{PD}\left(\mathrm{x}_{\mathrm{i}}\right)$,Partial derivative of component $\mathrm{x}_{\mathrm{i}}$ obtained for most of the components are either inexact or are faulty in expression and computations are wrong. All other mistakes also have not only been pointed but have been corrected also. A New CIM (NCIM) proposed, which highlights the above issues and have done desired calculations. The new CIM which has been advanced is computationally simpler and yields the desired ranking of components.
\end{abstract}

Index Terms: Importance Measure, Cost IM, Reliability, cost- risk analysis.

(C) 2015 Published by MECS Publisher. Selection and/or peer review under responsibility of the Research Association of Modern Education and Computer Science.

\section{Introduction}

Importance measures in reliability engineering are used to prioritize the components for improving the reliability and maintenance. To ensure the proper reliability of the system, component criticality can be identified and configured from the result of these measures. With the help of importance measure reliability of the system can be improved during the operation period also by prioritizing the maintenance planning.

\footnotetext{
* Corresponding author. Tel.: +91-9034184518

E-mail address: ramnitkkr@gmail.com
} 


\section{Nomenclature}

$\begin{array}{ll}\text { BE } & \text { Basic Event } \\ \text { CEIM } & \text { Cost Effective Importance Measure } \\ \text { CIM } & \text { Cost Important Measure } \\ \text { FV } & \text { Fussell-Vesely } \\ \text { IM } & \text { Important Measure } \\ \text { IP } & \text { Improvement Potential } \\ \text { NCIM } & \text { New Cost Important Measure } \\ \text { RAW } & \text { Risk Achievement Worth } \\ \text { RBD } & \text { Reliability Block Diagram } \\ \text { RRW } & \text { Risk Reduction Worth }\end{array}$

Component importance like Birnbaum, Fussell-Vesely (FV), Reliability Achievement Worth (RAW), and Reliability Reduction Worth (RRW) has been studied by many authors [2-5]. Zhu et al. [4] considered the patterns of the Birnbaum importance measures in linear consecutive k -out-of-n systems. For the topographic importance of the positions of components in system with structural importance measures have been developed in [5]. Joint reliability importance (JRI) measures for two edges in an undirected network are introduced by Hong \& Lie in [6].The importance measures for dynamic systems have been studied in [7-8]. Depending on the complex and networking characteristics the reliability assessment of combat system was illustrated by Wang et al. in [12]. Connectivity has been considered as the main reliability index and the reliability measurement based on the connectivity was defined in different ways [12]. Risk based measures are useful in recognizing weak components and help in increasing the overall system reliability. Risk based importance measures improvement potential (IP) and Risk Achievement Worth (RAW) were used in risk and reliability analysis of substation automation systems to rank the components according to impact on the system adequate performance in [13]. For appropriate component selection in software industry an integrated and improved component selection framework was given by W.G. Alghabbana in [14] by including pliability metric to cut down the time and cost. Pliability is a flexible measure that measure software quality.

Risk based measures are used to evaluate the feature's importance in further reducing the risk and its importance in maintaining the present risk level. When interpreting component importance, Rausand and Hoyland concluded that the importance of a component should depend on the following factors [9]:

- The Component location in the system.

- Component reliability

But the importance of a component or system also depends on the cost of the maintaining in a specified interval $(0, \mathrm{t})$. However, to improve the overall system reliability, cost issue in selecting the individual component of a system plays major role as the purpose of improving the reliability is to prolong the system lifetime and to save the maintenance cost. The classical measures do not take the component cost consideration. The problem of reliability allocation may be treated as cost minimization under the required reliability or safety in the system designing. Reliability allocation through cost minimization is considered in [10]. Cost effective importance measure (CEIM) that considers the components performance, system structure and economic aspects has been proposed by S. Gupta et al. in [15]. The proposed measure CEIM was used in criticality analysis of different components and resource prioritization in a production plant [15]. Recently some work has appeared on Cost Importance Measure (CIM) [1]. This paper addresses shortcomings of the paper [1] and a new cost related importance measure.

The rest of the paper is organised as Section 2 gives basic CIM. Section 3 presents New CIM proposed. In Section 4 an example is considered to demonstrate the effectiveness of proposed CIM. Section 5 concludes the 
paper.

\section{Cost Importance Measure}

CIM can be used to know the cost-risk efficiency of each component in the system which will be useful to analyst to guide the activities needed in system design and maintenance.

CIM can be expressed as [1]

$$
\operatorname{CIM}\left(x_{i}\right)=\frac{\frac{P D\left(x_{i}\right)}{c_{i}^{\prime}\left(x_{i}\right)} d c_{i}}{\sum_{k=1}^{n} \frac{P D\left(x_{k}\right)}{c_{k}^{\prime}\left(x_{k}\right)} d c_{k}}
$$

Where $c_{i}\left(x_{i}\right)$ be the cost function and $x_{i}$ be the mean failure probability of component $\mathrm{i}$. $\mathrm{R}$ be the risk metric of the system. By considering three conditions that $c_{i}$ is a positive definite function, is non increasing and also increases rapidly as $\mathrm{x}_{\mathrm{i}}$ gets close to one.

$\mathrm{PD}\left(\mathrm{x}_{\mathrm{i}}\right)=\partial R\left(x_{i}\right) / \partial x_{i}$ is the IM of Partial derivative.

$d c_{i}=c_{i}\left(x_{i}+\Delta x_{i}\right)-c_{i}\left(x_{i}\right)$ is the fraction change of the cost in component $\mathrm{i}$.

It can be observed that the result of the measure depends on the variations in $\mathrm{dc}_{\mathrm{i}}$

CIM has additive property also.

If we consider the CIM of the subset of the parameters $x_{i}, x_{j}, \ldots \ldots \ldots x_{p}$.

Then,

$\operatorname{CIM}\left(x_{i}, x_{j, \ldots \ldots \ldots, \ldots}, x_{p}\right)=\frac{\frac{P D\left(x_{i}\right)}{c_{i}^{\prime}\left(x_{i}\right)} d c_{i}+\frac{P D\left(x_{j}\right)}{c_{j}^{\prime}\left(x_{j}\right)} d c_{j}+\cdots+\frac{P D\left(x_{p}\right)}{c_{i}^{\prime}\left(x_{p}\right)} d c_{p}}{\sum_{k=1}^{n} \frac{P D\left(x_{k}\right)}{c_{k}^{\prime}\left(x_{k}\right)} d c_{k}}$

Hence CIM $\left(\mathrm{x}_{\mathrm{i}}, \mathrm{x}_{\mathrm{j}}, \ldots \ldots \ldots \mathrm{x}_{\mathrm{p}}\right)=\operatorname{CIM}\left(\mathrm{x}_{\mathrm{i}}\right)+\operatorname{CIM}\left(\mathrm{x}_{\mathrm{j}}\right)+\ldots .+\mathrm{CIM}\left(\mathrm{x}_{\mathrm{p}}\right)$

\section{Proposed CIM}

A new CIM which is computationally simpler and yields the desired ranking of components is presented in this section. The New CIM (NCIM) is expressed by assuming the same terminology used in section II

$$
\operatorname{NCIM}\left(x_{i}\right)=\frac{\frac{P D\left(x_{i}\right)}{c_{i}^{\prime}\left(x_{i}\right)} d c_{i}}{c_{s}}
$$

Where $c_{s}=\sum_{k=1}^{n} c_{k}, c_{i} \rightarrow c_{i}^{\prime}\left(x_{i}\right)$.

The proposed CIM also obeys additive property with subset of components CIM. If we consider the CIM of the subset of the parameters $x_{i}, x_{j}, \ldots \ldots \ldots x_{p}$

Then, 
$\operatorname{NCIM}\left(x_{i}, x_{j, \ldots \ldots \ldots . .,}, x_{p}\right)=\frac{\frac{P D\left(x_{i}\right)}{c_{i}^{\prime}\left(x_{i}\right)} d c_{i}+\frac{P D\left(x_{j}\right)}{c_{j}^{\prime}\left(x_{j}\right)} d c_{j}+\cdots+\frac{P D\left(x_{p}\right)}{c_{i}^{\prime}\left(x_{p}\right)} d c_{p}}{c_{s}}$

where $c_{s}=\sum_{k=1}^{n} c_{k}, c_{i} \rightarrow c_{i}^{\prime}\left(x_{i}\right)$

\section{Results and Discussion}

By considering a Double Bridge Network as an example, the CIM considered in section 2 and NCIM in section 3 are evaluated for all the components and the results of both are discussed.

The cost function of each component of the Pareto growth model [11] is defined by

$$
c_{i}\left(x_{i}\right)=\left(\frac{a_{i}}{x_{i}}\right)^{\frac{1}{b_{i}}}-\varepsilon_{i}
$$

where $a_{i}, b_{i}, \varepsilon_{i}$ are constants for each BE. This parato class of failure distribution has an advantage of its exponential generalisation.

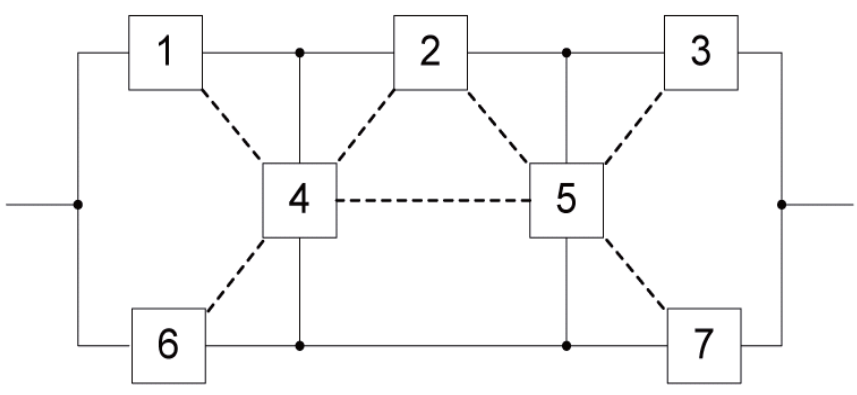

Fig 1. Double-Bridge Network

Fig.1 shows the Reliability Block Diagram of Double Bridge Network and parameters of the network are given in Table. 1

Table1. Parameters for the Double-Bride Network

\begin{tabular}{ccccc}
\hline \multirow{2}{*}{ Component } & \multirow{2}{*}{ Mean failure Probability } & \multicolumn{3}{c}{ Parameter } \\
\cline { 3 - 5 } & & $\mathrm{a}$ & $\mathrm{b}$ & $\boldsymbol{\varepsilon}$ \\
\hline 1 & 0.01 & 2 & 0.8 & 0 \\
2 & 0.015 & 1.5 & 0.86 & 0 \\
3 & 0.01 & 2 & 0.8 & 0 \\
4 & 0.03 & 1 & 0.6 & 0 \\
5 & 0.03 & 1 & 0.6 & 0 \\
6 & 0.01 & 2 & 0.8 & 0 \\
7
\end{tabular}


The minimal cut sets of the network are: $\{1,6\},\{3,7\},\{2,4,6\},\{2,5,7\},\{1,4,5,7\},\{3,4,5,6\}$. The system failure function can be expressed as a function in terms of failure probabilities is

$$
F=x_{1} x_{6} \cup x_{3} x_{7} \cup x_{2} x_{4} x_{6} \cup x_{2} x_{5} x_{7} \cup x_{1} x_{4} x_{5} x_{7} \cup x_{3} x_{4} x_{5} x_{6}
$$

By assuming that components 1, 3, 6, 7 are identical. Similarly 4 and 5 also identical. The cost parameters and the unavailability of these components are given in Table1. To find the CIM first we need to find the derivatives of $\mathrm{F}$ with respect to $\mathrm{x}_{\mathrm{i}}$. In [1] the derivatives calculated were not exact.

It is given that $\frac{\partial F}{\partial x_{1}}=x_{6}$

But it should be $\frac{\partial F}{\partial x_{1}}=x_{6}+x_{4} x_{5} x_{7}$

Also the CIM measured with formula used and stated in the same paper were different. In this paper the results were recalculated and given in Table2. For the same case the component measure is calculated with the proposed CIM and the results were tabulated in Table2.

Table2.CIM and NCIM for individual Basic Events of the Network

\begin{tabular}{cccccccc}
\hline Components & 1 & 2 & 3 & 4 & 5 & 6 & 7 \\
\hline CIM[1] & 0.2209 & 0.0759 & 0.2209 & 0.01012 & 0.01012 & 0.23092 & 0.23092 \\
NCIM & 2.566 & 1.48 & 2.566 & 1.85 & 1.89 & 2.783 & 2.783 \\
\hline
\end{tabular}

From the results of the measures it can be observed that the CIM and NCIM give approximately similar results. Components 6 and 7 are most important in the structure than 1 and 3 even though all 1,3,6,7 are identical. Then components 4 and 5 are important. Component 2 has least ranking for both measures. However the proposed CIM is much simpler and fewer computations required in yielding desired ranking of components.

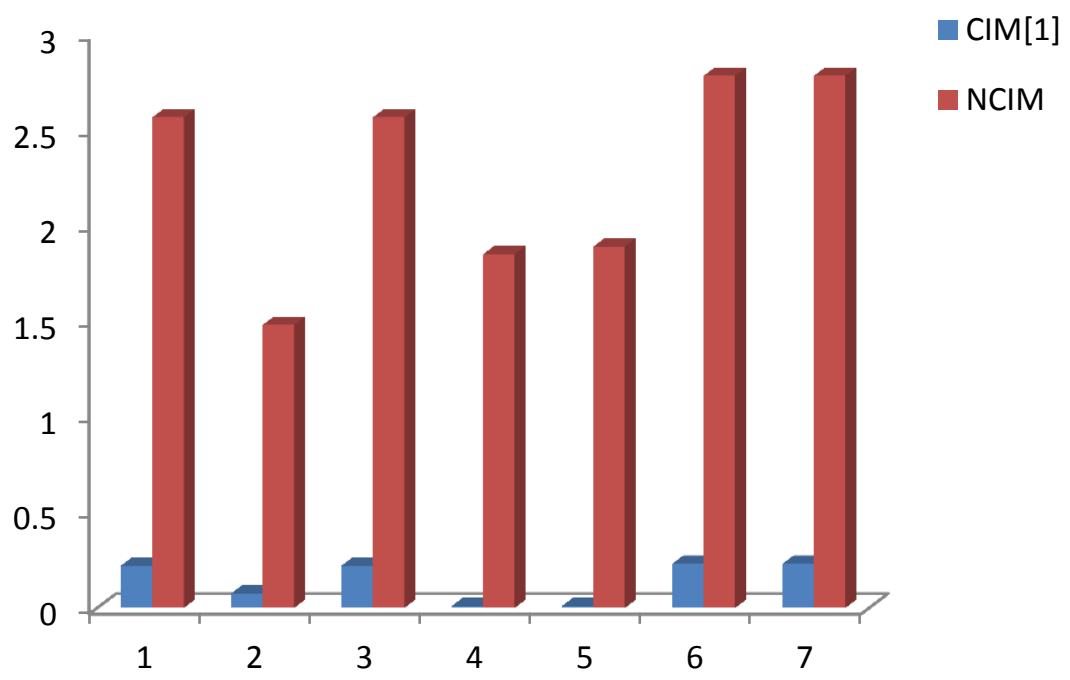

Fig 2. CIM and NCIM for individual Basic Events of the Network 
The pictorial representations in Figure 2, depicts the comparison of existing and proposed CIM in an effective manner. CIM of multiple components is the sum of the individual component CIM's. The combined CIM of 1 and 2 can be calculated as

$\operatorname{CIM}\left(\mathrm{x}_{1} \cup \mathrm{x}_{2}\right)=\operatorname{CIM}\left(\mathrm{x}_{1}\right)+\operatorname{CIM}\left(\mathrm{x}_{2}\right)=0.2968$

Similarly for NCIM:

$\operatorname{NCIM}\left(\mathrm{x}_{1} \cup \mathrm{x}_{2}\right)=\operatorname{NCIM}\left(\mathrm{x}_{1}\right)+\operatorname{NCIM}\left(\mathrm{x}_{2}\right)=4.046$

In this manner any set of multiple component importance measure can be calculated from their individual CIM's.

\section{Conclusion}

The importance measures are used in the reliability analysis of systems and describe how a particular component affects the system reliability. Basic IM do not include the cost matter in the ranking of component importance. But cost of a system is a critical issue in both economic and maintenance aspects, cost based measures are useful in ranking the components of system in such case. CIM gives the cost-risk prioritization for all the components of the system and aids the analyst in system designing and maintenance. In this paper the shortcomings of the recently proposed CIM have been highlighted and corrections applied and a new CIM has been advanced which is simpler, computationally more efficient and gives justifiable accurate ranking to the components.

\section{Acknowledgements}

This work was supported by the Ministry of Human Resources and Development (MHRD), New Delhi, India. The authors are thankful for the valuable comments and suggestions from the esteemed reviewers which have improved the strength and quality of the paper.

\section{References}

[1] Ming Xu, Wencong Zhao, Xianhui Yang "Cost-related importance measure", 2011 IEEE International Conference on Information and Automation (ICIA), pp.644,649, 6-8 June 2011.

[2] Z. Birnbaum, "On the importance of different components in a multi component system", Multivariate Analysis, vol.2, Academic Press, New York, 1969, pp.581-592.

[3] J.B. Fussell, "How to hand-calculate system reliability and safety characteristics", IEEE Transactions on Reliability R-24 (3) (1975) 169-174.

[4] X. Zhu, Q. Yao, W. Kuo, "Patterns of the Birnbaum importance in linear consecutive k-out-of-n systems," IIE Transactions, vol. 44, 2012.

[5] F. C. Meng, "Comparing the importance of system elements by some structural characteristics," IEEE Trans. Reliability, vol. 45, pp. 59-65, 1996.

[6] J. S. Hong, C. H. Lie, "Joint reliability-importance of two edges in an undirected network," IEEE Trans. Reliability, vol. 42, pp. 17-23, 1993.

[7] J. D. Andrews, "Birnbaum and criticality measures of component contribution to the failure of phased missions," Reliability Engineering \& System Safety, vol. 93, pp. 1861-1866, 2008.

[8] P. D. Van, A. Barros, C. Berenguer, "Reliability importance analysis of Markovian systems at steady state using perturbation analysis," Reliability Engineering \& System Safety, vol. 93, pp. 1605-1615, 2008.

[9] M. Rausand, A. Høyland, System Reliability Theory: Models, Statistical Methods, and Applications, John Wiley \& Sons, New Jersey, 2004.

[10] A.O.Charles, C.Chu, "Reliability allocation through cost minimization," IEEE Trans on Reliability, vol. 
52, no. 1, pp. 106-111, 2003.

[11] M. R. Lyu, "Optimal allocation of test resources for software reliability growth modeling in software development," IEEE Trans on Reliability, vol. 51, no. 2, pp. 183-192, 2002.

[12] X.Wang, Sen Li, F.Liu, X Fan, "Reliability analysis of combat architecture model based on complex network", International Journal of Engineering and Manufacturing, vol. 2, no.2, pp.15-22, 2012.

[13] R.K.Rao Alla, Pahuja G.L, Lather J.S., "Importance measures based risk and reliability analysis of substation automation systems," 2014 Annual IEEE India Conference (INDICON), pp.1-5, 11-13 Dec. 2014.

[14] W.G. Alghabbana, M.R.J Qureshi, "Improved Framework for Appropriate Components Selection", International Journal of Engineering and Manufacturing, vol. 4, no.1, pp.18-24, 2014.

[15] S.Gupta et al., "Cost Effective Importance Measure -A new approach for resource prioritization in a production plant", International Journal of Quality \&Reliability Management, vol. 30, no. 4, 2013.

\section{Author(s) Profile}

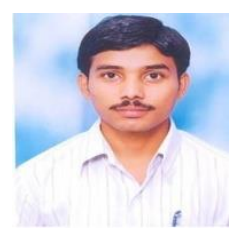

RamaKoteswaraRao Alla has graduated in Electrical and Electronics Engineering from JNTU Hyderabad. He did his M.Tech (Control Systems) in Electrical Engineering Department from National Institute of Technology Kurukshetra. Currently he is pursuing his $\mathrm{PhD}$ from Electrical Engineering Department NIT Kurukshetra. His research interests include Reliability Engineering and Control of Time Delay Systems.

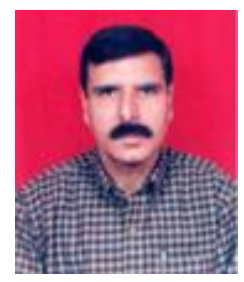

Prof. G.L.Pahuja did his B Sc (Electrical Engineering), M Tech (Control System), and PhD in the area of Reliability Engineering from REC Kurukshetra affliated to Kurukshetra University Kurukshetra. He is currently working as a professor in department of Electrical Engineering, National Institute of technology kurukshetra. He has 31 years of teaching experience. His research intrests include System and Reliability Engg, Fault tolerant systems, Reliability evaluation and optimization of communication networks.

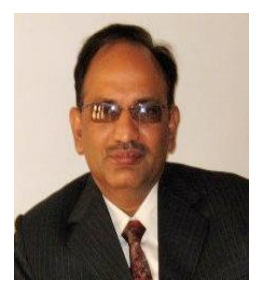

Prof. J.S.Lather has graduated in Electrical Engneering fron REC Surat. He did his M.Tech(Control Systems) and PhD in the area of Robust Control from REC Kurukshetra. $\mathrm{He}$ is currently working as a professor in the department of Electrical Engineering, National Institute of Technology Kurukshetra,India. He has 20 years of teaching experience. His research intrests include Robust Control, Time Delay Systems.

How to cite this paper: RamaKoteswara Rao Alla, G.L Pahuja, J.S Lather,"Risk Based Ranking Using Component Cost Importance Measure", IJEM, vol.5, no.1, pp.26-32, 2015.DOI: 10.5815/ijem.2015.01.03 